\title{
Cuerpos (h)errados: mujer y prisión en la narrativa cubana contemporánea
}

\author{
Ana CASADO FERNÁNDEZ \\ Universidad Complutense de Madrid \\ anacasado@filol.ucm.es
}

\section{RESUMEN}

La obra testimonial de Ofelia Domínguez Navarro De 6 a 6: la vida en las prisiones cubanas (1937) y la novela de Agnieska Hernández Díaz San Lunes: panóptico en dos estaciones (2009) profundizan en las relaciones de poder dentro del espacio de la prisión. Analizaremos estas dos obras literarias que se vinculan en la construcción de lo femenino en tanto que identidad dentro de este espacio deformador y alienante que se convierte en un reflejo del espacio social exterior.

Palabras clave: literatura carcelaria, mujer, cuerpo, poder, Cuba

\begin{abstract}
The testimonial of Ofelia Domínguez Navarro called De 6 a 6: la vida de las prisiones cubanas (1937) and the novel San Lunes: panóptico en dos estaciones (2009) by Agnieska Hernández Díaz deal with the power relationships in depth inside the prison space. We will analyse these two literary works that are linked by the construction of the feminine as identity in this deforming and dehumanizing space that becomes a reflection of the external social space.
\end{abstract}

Keywords: prison literature, woman, body, power, Cuba.

Sumario: 1. De 6 a 6: la verdad arrancada de los muros de la cárcel 2. San Lunes: la autodestrucción del Panóptico y su proyección al exterior

El espacio presidiario en la literatura cubana toma nuevos perfiles con la mujer como autora y como protagonista. La cárcel se presenta como un monstruo que devora mujeres, una máquina infernal que elimina identidades donde el cuerpo 
sometido de la presa experimenta ese "dolor infinito" martiano ${ }^{1}$-físico y psicológico- ante el cuerpo que somete.

La literatura carcelaria cubana femenina ${ }^{2}$ plantea distintas cuestiones interesantes con respecto al género literario utilizado para abordar el espacio de la prisión. ¿Bajo qué forma adentrarse en esa entraña monstruosa vigilada, cubierta de enfermedad, vicio o locura? ¿Utilizando el testimonio para proyectar de cerca, desde una primera persona, ese inframundo habitado por seres marginales o, por el contrario, la ficción, para tomar distancia y hacer la denuncia de una forma menos directa? ¿Quizás formar un híbrido entre realidad y ficción para llegar a lo que se ha llamado la novela testimonial?

Sin duda, la temática carcelaria parte en numerosas ocasiones de una experiencia de vida, tal es el caso de Ofelia Domínguez Navarro, pero también puede utilizarse como materia literaria para la creación de obras ficcionales como en Agnieska Hernández Díaz. Las obras de estas dos escritoras cubanas pertenecen a dos épocas muy distintas: Ofelia Domínguez se inscribe en la primera mitad del siglo XX y Agnieska Hernández a finales del mismo y principios del siglo XXI; mientras el testimonio de la primera está muy vinculado al contexto histórico de la época, la llamada revolución del 30 y la dictadura de Gerardo Machado, en la novela de Hernández Díaz no encontramos un referente temporal específico dentro de la historia narrada. Sin embargo, esta segunda obra se publica en un momento en el que las estructuras de poder cubanas -al igual que en la época de los años treinta durante el machadato- ejercen un control sobre el individuo comparable a los mecanismos totales de vigilancia y dominio llevados a cabo en la cárcel ${ }^{3}$.

${ }^{1}$ Para José Martí el dolor físico en la prisión se convierte también en dolor psíquico; así describe su propia experiencia en El presidio político en Cuba (1871): "Dolor infinito debía ser el único nombre de estas páginas. Dolor infinito, porque el dolor del presidio es el más rudo, el más devastador de los dolores, el que mata la inteligencia, y seca el alma, y deja en ella huellas que no se borrarán jamás”. J. Martí (1995), p. 37.

${ }^{2}$ Aunque el artículo se centre solamente en dos obras de literatura carcelaria cubana escrita por mujeres (De 6 a 6 de Ofelia Domínguez Navarro y San Lunes de Agnieska Hernández Díaz), debemos destacar la existencia de otras obras de gran valor dentro de esta temática como son dos libros testimoniales escritos en los años treinta Estampas de la cárcel de Edelmira González y Presidio Modelo de Ángeles Caiñas Ponzoa, así como varias obras en torno al presidio político de mujeres durante el régimen castrista: Diary of a survivor. Ninenteen years in a Cuba Women's Prison (1995) de Ana Rodríguez y Gleen Garvin y la novela testimonial Dios en las cárceles de Cuba (2001) de María Elena Cruz Varela.

${ }^{3}$ La metaforización de la isla de Cuba en cárcel comienza con José Martí en un discurso que pronunció en honor al poeta José María Heredia en Nueva York, el 30 de noviembre de 1889: "Y Cuba, tan bella como Grecia, tendida así entre hierros, mancha del mundo, presidio rodeado de agua, rémora de América”. J. Martí (1975), p. 168. Pablo de la Torriente Brau, escritor y preso político durante los años treinta al igual que Ofelia Domínguez, también establece un vínculo entre Cuba y el presidio en esa época revolucionaria; en su 
Asimismo, el discurso de ambas autoras se aproxima en la representación del espacio carcelario como un lugar mísero y abyecto donde las presas -dóciles ${ }^{4}$, moldeables, transformables- son sometidas a condiciones de vida infrahumanas y a brutales castigos, lo que pone en cuestión el llamado objetivo reformista de la cárcel, que más que reformar, deforma.

\section{De 6 a 6: la verdad arrancada de los muros de la cárcel}

Ofelia Domínguez Navarro escribe su obra testimonial De 6 a 6: la vida en las prisiones cubanas - publicada como libro en México en 1937 aunque anteriormente había aparecido en una serie de artículos en el periódico cubano Ahora del 1 de abril al 20 de mayo de $1934^{5}$ - tras su propia experiencia en el Castillo del Príncipe, Guanabacoa y el Salón de Penados del Calixto García. Arrestada como presa política en los tumultuosos años treinta contra el régimen del general Gerardo Machado ${ }^{6}$, Ofelia Domínguez nos relata sus vivencias en distintas cárceles de Cuba (centrándose principalmente en la de Guanabacoa) desde un yo que ha vivido y respirado la atmósfera carcelaria y que por ello, afirma, es capaz de mostrar la verdad que allí dentro se esconde. Su formación en Derecho (en 1922 se convierte en la primera notaria en Cuba), su defensa de la mujer en la Alianza Nacional Feminista y Unión Laborista de Mujeres, así como su participación en la Revolución del 30 contra el gobierno de Machado, convierten el testimonio de Ofelia Domínguez en un libro fundamental cuyo objetivo principal es la denuncia de un sistema penitenciario inválido y estéril ${ }^{7}$ en una época de terror dictatorial ${ }^{8}$.

serie "105 días preso" afirma que la dictadura de Machado convierte a la isla en un presidio y a todos los cubanos en presidiarios: "Los muchachos ya están en la calle, libres, dentro de todo un pueblo preso. Porque el pueblo está preso". P. Torriente (2009), p. 84-85. Asimismo, la dictadura castrista también ha generado diversas imágenes sobre la isla-prisión o ciudad-prisión, podríamos poner de ejemplo las obras de Reinaldo Arenas Antes que anochezca (1992) y Viaje a La Habana (1990).

${ }^{4}$ Foucault analizó en Vigilar y castigar la maquinaria carcelaria y la posición del cuerpo del preso en ella -su docilidad, moldeabilidad, transformabilidad-como "objeto y blanco de poder". M. Foucault (2009), p. 158.

${ }^{5}$ A. Cairo (1993), p. 79.

${ }^{6}$ Ofelia Rodríguez Navarro luchó contra Gerardo Machado junto a otras mujeres revolucionarias como Flora Díaz Parrado, Ofelia Rodríguez Acosta, Loló de la Torriente o Teté Casuso. Pablo de la Torriente Brau recuerda el papel de la mujer en la lucha revolucionaria en el artículo "Las mujeres contra Machado" incluido en Testimonios y reportajes (2009). Este periodista y escritor también denunció el sistema penitenciario cubano de los años del machadato y la cruel maquinaria carcelaria ejercida contra los presos en sus series "105 días preso" (1931, periódico El Mundo), "La isla de los 500 asesinatos" (1934, periódico Ahora) y el libro Presidio Modelo (1969).

${ }^{7}$ Susana A. Montero señala distintas tendencias en la narrativa cubana escrita por mujeres entre 1923 y 1958. El libro de Ofelia Domínguez se insertaría en las narraciones de 
La experiencia de Ofelia Domínguez -"lo que viví, miré y oí; lo que pienso y siento" - se convierte en palabra: "dar a conocer en toda su repelente desnudez, ese pudridero que se denomina Prisión Nacional de Mujeres" $"$. Realidad y crudeza unidas en las descripciones; dolor y enfermedad, impotencia y desasosiego recorren los cuerpos de mujeres presas, inmersas en un sistema pútrido al que se doblegan sin remedio. Los adjetivos y sustantivos encargados de describir el espacio presidiario de mujeres ("repelente", "amargo", "entenebrecido", "torpe"; "vertedero", "pudridero") nos remiten a un inframundo sórdido en el que se establecen una serie de relaciones de poder y control sobre las presas para ejecutar eficazmente la incompetente maquinaria penitenciaria. El llamado "cuerpo político" ${ }^{11}$ se proyecta perfectamente en las páginas de este libro ya que las presas son objeto de poder ante un sistema y empleados que deciden no proporcionar condiciones higiénicas adecuadas ni alimento, cometer abusos y vejaciones o permanecer indiferentes ante la descarnada realidad. Debido al acatamiento de este poder de control por parte de algunas mujeres, otro de los aspectos que se pone en cuestión en la obra de Ofelia Domínguez es la despersonalización de la presa como individua:

El horizonte lejano de la libertad las hace comportarse dóciles y sumisas, trabajadoras y diligentes [...] Estas mujeres se adaptan al reglamento y evitan tomar parte en las frecuentes revueltas del penal. No protestan de nada. Tratan de aliarse a las autoridades de la cárcel [...] Representan el tipo medio de la mujer

tendencia social o sociopolítica - "en las narraciones de tendencia social encontramos repetidos, por supuesto, los planteamientos ideológicos ya citados (antifascismo, antibelicismo, crítica a la intervención norteamericana, patriotismo), por ser la denuncia social el primer objetivo de sus escritoras." S. Montero (1989), p. 23-, pero al mismo tiempo en las narraciones de tendencia feminista por su defensa de los derechos de la mujer y la demostración de su "capacidad emocional, física e intelectual (laboral, ideológica, directiva)", p. 12.

${ }^{8}$ La escritora relaciona el estado y funcionamiento de las prisiones con el momento político que vivía Cuba bajo la dictadura de Machado: "El Príncipe, Guanabacoa y el Presidio Modelo [...] La Cabaña, Atarés, San Severino y otras viejas fortalezas coloniales [...] son los monumentos más elocuentes a la barbarie penitenciaria de una época en que el terror y el abuso de la fuerza, aparecen como las características más salientes del poder". O. Domínguez Navarro (1937), p. 61.

${ }^{9}$ O. Domínguez Navarro (1937), p. 17.

${ }^{10}$ O. Domínguez Navarro (1937), p. 17.

${ }^{11}$ Foucault analiza las relaciones entre cuerpo y campo político tomando el concepto de "cuerpo político" para el análisis de las relaciones de poder y subordinación en los establecimientos penitenciarios: "El cuerpo está también directamente inmerso en un campo político. Las relaciones de poder lo convierten en una presa inmediata; lo cercan, lo marcan, lo doman, lo someten a suplicio, lo fuerzan a trabajos, lo obligan a ceremonias, exigen de él signos". M. Foucault (2009), p. 35. 
en general, de la mujer de su casa, y encajan dentro de la normalidad establecida por la ley y la costumbre. Esa normalidad que borra perfiles, empalidece tonalidades y que sólo sirve para engendrar seres despersonalizados ${ }^{12}$.

Ofelia Domínguez relaciona el comportamiento de la mujer en el espacio carcelario -el cuerpo no resistente que se adapta al nuevo espacio represivo sin ponerlo en cuestión - con el de el espacio de la casa- donde igualmente asume un cuerpo sumiso y obediente "por ley". En este sentido, el discurso de Domínguez es una reivindicación del sujeto mujer y un llamamiento al cambio de posición pasiva y sumisa, asumido con normalidad en distintos espacios (ya sea la cárcel, la casa o la calle), a una posición activa y subversiva como en el caso del grupo de las revolucionarias de los años treinta del que forma parte la misma autora. Sin embargo, existen en ese espacio carcelario mujeres que rompen con esa posición sumisa como la llamada "la Chunga", que posee un estatus de poder con respecto a las otras presas, es la líder y se la respeta, por lo que representa el cuerpo rebelde de mujer -el cuerpo resistente- que defiende Ofelia Domínguez: "desafiaba indiferente, casi con indolencia despreciativa, a las autoridades del penal [...] era capaz de llevar a todas las presas a la desobediencia, importándole poco las amenazas" $" 13$.

El espacio carcelario se presenta como un microcosmos que refleja la condición de la mujer en el espacio exterior. Entre las mujeres que pueblan las cárceles Domínguez se detiene especialmente en las prostitutas - "desde la esquelética fleterita, hasta la célebre e influyente dueña de casas de negocios" $" 14$ - para criticar la asunción del cuerpo femenino como mercancía y su condición de víctimas y esclavas en el engranaje social. Asimismo destaca la utilización de la brujería en estas presas -"limpian, vencen, quitan malas influencias, dominan y amarran"- con el fin de conservar al hombre: "el hombre es el eje de todas estas actividades. Es amo y cliente. Precisa movilizar toda esa baraúnda de creencia a fin de conservarlo. No importa que al mismo tiempo el hombre sea su verdugo"15. La intención de la escritora es subrayar de nuevo la posición de sumisión/obediencia que asume la mujer con respecto al chulo que la controla y domina y con el cual establece un vínculo de dependencia enfermiza. Este rol de la mujer como cuerpo dócil y doblegado ante el hombre es el mismo que el sistema penitenciario pretende que contraiga la mujer presa dentro del espacio carcelario y es precisamente lo que la autora critica con ferocidad.

Por otro lado, la cárcel de mujeres se presenta como un establecimiento disciplinario en el que se acatan unas normas y la vigilancia se convierte en el

12 O. Domínguez Navarro (1937), p. 19.

${ }^{13}$ O. Domínguez Navarro (1937), p. 29.

${ }^{14}$ O. Domínguez Navarro (1937), p. 19-20.

${ }^{15}$ O. Domínguez Navarro (1937), p. 23. 
motor de control por excelencia. El título De 6 a 6 alude a esta disciplina ${ }^{16}$, que forma parte de ese poder de control y que es señalizada con el sonido de un timbre: "Un solo timbrazo, largo y sostenido. Las seis. Murmullo de voces y de risas. El penal se despierta. Se ha roto el silencio de doce horas. Las rejas, libres ya de los cerrojos, vomitan al patio el turbulento contenido de las galeras" ${ }^{\text {"17 }}$. Las vigilantes son las que ejercen el control de las presas a través de la mirada ${ }^{18}$-"acechan y vigilan todos nuestros actos"19- y utilizan su poder para castigar a sus subordinadas con el calabozo u otro tipo de pena. Para la escritora no son más que "simples instrumentos de un sistema bárbaro, donde el abuso y la violencia tienen prerrogativas incalculables"20. La prisión se convierte en estercolero o ciénaga donde las presas a modo de animales - son llamadas "bestias heridas" o "bestias herradas"- se revuelcan ante un poder superior que las aniquila y destruye. La docilidad convierte a la presa en perfecto instrumento de dominio por parte del sistema: "la perfecta penada es para las autoridades carcelarias, la que se pliega dócil y sumisa a sus imposiciones: la que aguanta como bestia doméstica el golpe y sufre el castigo" ${ }^{21}$. El objeto de corregir y reformar en la prisión está basado en el abuso y el castigo; las vigilantes quieren mantener su posición de cuerpo dominante -el "aquí no manda nadie más que yo"22 - frente al cuerpo dominado de las presas.

La escritora toma la voz como presa política en su utilización de "nosotras" pero su discurso se dirige también a las presas comunes de las que vive separada. Semejante a otros textos de literatura carcelaria ${ }^{23}$, Ofelia Domínguez retrata la

\footnotetext{
${ }^{16}$ Foucault concede gran importancia a los mecanismos disciplinarios para llevar a cabo el control del individuo en las prisiones: "A estos métodos que permiten el control minucioso de las operaciones del cuerpo, que garantizan la sujeción constante de sus fuerzas y les imponen una relación de docilidad-utilidad es a lo que se puede llamar «disciplinas»". M. Foucault (2009), p. 159. Asimismo en La vida de los hombres infames (1990) Foucault vuelve a retomar el concepto de disciplina y la define de esta manera: "La disciplina es ante todo un análisis del espacio; es la individualización por el espacio, la colocación de los cuerpos en un espacio individualizado que permita la clasificación y las combinaciones. [...] La disciplina es una técnica de poder que encierra una vigilancia perpetua y constante de los individuos". M. Foucault (1990), p. 164-165.

${ }^{17}$ O. Domínguez Navarro (1937), p. 27.

${ }^{18}$ La mirada es el mecanismo de control por excelencia del espacio presidiario y del cuerpo del preso. La mirada total se establece con el modelo panóptico de Bentham que Agnieska Hernández toma como base para el desarrollo de su novela San Lunes.

${ }^{19}$ O. Domínguez Navarro (1937), p. 31.

${ }^{20}$ O. Domínguez Navarro (1937), p. 31.

${ }^{21}$ O. Domínguez Navarro (1937), p. 49.

${ }^{22}$ O. Domínguez Navarro (1937), p. 50.

${ }^{23}$ Como es el caso de Carlos Montenegro, escritor cubano que se formó entre los muros del presidio y que permaneció allí casi doce años, de 1919 a 1931. Montenegro en su obra narrativa -los cuentos de presidiarios incluidos en El renuevo y otros cuentos (1929) y Dos
} 
prisión como un espacio oculto y marginal, una entraña envenenada que contiene lo más sórdido del ser humano: "En el penal el ambiente es caliginoso, áspero, agrio. Trasuda rencor, odio, lujuria, resentimiento, venganza. Hasta la risa tiene un raro sabor" ${ }^{24}$. Esta miseria "fisiológica y moral" que se origina en el espacio del presidio se proyecta en los cuerpos enfermos y las mentes aniquiladas. Ofelia Domínguez denuncia en su texto las condiciones de vida insalubres y la inanición que sufren muchas de las presas, lo cual supone una transgresión del Reglamento de la cárcel. El cuerpo femenino será representado como un cuerpo sufriente/un cuerpo herido sobre el que recae ese sistema monstruoso. El contagio de enfermedades por la falta de higiene y atención médica tiene como resultado un "montón de carne podrida" o "carne rota". Y las víctimas mayores de esta tragedia son los niños que conviven con sus madres enfermas: "estas vidas que empiezan y que ya llevan en la sangre la sentencia de muerte" ${ }^{25}$.

\section{San Lunes: la autodestrucción del Panóptico y su proyección al exterior}

La narrativa ficcional es el género elegido por Agnieska Hernández para adentrarse en el universo carcelario. Su mayor aportación a la literatura carcelaria viene de la mano de la novela San Lunes: panóptico en dos estaciones (2009) ${ }^{26}$. Esta novela pone en cuestionamiento la supuesta perfección del sistema panóptico carcelario $^{27}$, transgrediendo así la organización de poder que lo mantiene y abriendo fisuras en una estructura donde la vigilancia y el control se han convertido en sus máximas.

En los distintos espacios donde se sitúa la narración (las celdas, los talleres, el patio, el comedor) encontramos a una mujer, que como en Ofelia Domínguez, se aproxima a lo más animal de sí misma por la degradación a la que se ha visto sometida -"parecen animales, cuerpos que se deforman por el exceso de frijol y pan viejo" ${ }^{28}$ - El cuerpo femenino de nuevo no reformado sino deformado -"la prisión

barcos (1934); su novela Hombres sin mujer (1938)- y su obra testimonial -la serie de artículos titulada “«Suicidados», «Fugados» y Enterrados Vivos" publicada en la revista Carteles (1933-1934)- también retrata la prisión como un lugar mísero y degradado.

${ }^{24}$ O. Domínguez Navarro (1937), p.33.

${ }^{25}$ O. Domínguez Navarro (1937), p.44.

${ }^{26}$ También podemos destacar su libro de cuentos Sol negro (2010) en el que se incluyen varios relatos sobre la prisión de mujeres.

27 Jeremy Bentham diseñó en 1791 un modelo arquitectónico de cárcel que llamó "Panopticon" el cual constaba de una torre central de vigilancia y de un edificio periférico anular compuesto por celdas. Bentham lo define como una "casa de penitencia" cuya utilidad esencia es "la facultad de ver con una mirada todo cuanto se hace en ella". J. Bentham (1989), p.37.

${ }^{28}$ A. Hernández Díaz (2009), p.15. 
nos destruye a todas por igual" ${ }^{29}$ - en un espacio donde la vigilancia se extrema a través de una torre central que todo lo ve, el llamado "tótem". El sistema de poder y control de la cárcel se proyecta y refleja también en su interior, en el espacio carcelario existe entre las presas una relación de jerarquía por la que la llamada Jefa, la Morsa, se sitúa en un plano superior: "Era normal besar la mano de La Jefa, secarle los pies después del baño, dejarle un poco de comida y tratarla con mucho respeto" ${ }^{\prime 30}$.

Este sistema panóptico que muestra Agnieska Hernández en San Lunes se adapta perfectamente a la dicotomía de ver-ser visto de este tipo de diseño arquitectónico ${ }^{31}$ : "La torre que está en el centro de la prisión, esta torre de cristal que tú ves allí, es una mirada constante, capaz de espiarnos aunque no podamos ver a los inspectores que están dentro. Por eso nos portamos como santas, adaptadas a ese ojo descarado"32. La imposibilidad de actuar libremente, el poder y el querer, viene determinada por esta "mirada eterna" o "mirada superior" 33 que actúa como barrera ante un cuerpo que se va despersonalizando en este espacio opresivo.

El cuerpo resistente e insurrecto, aquel que reivindicaba Ofelia Domínguez, queda neutralizado por esta mirada total; las presas de San Lunes se convierten en cuerpos sumisos que adoran a esta torre central, especie de Dios omnipotente, y le dedican rezos y ofrendas para que las proteja y ayude: "[La Jefa] le pide al inspector de la torre que, por favor, no nos abandone, necesitamos sentirnos vivas y no ignoradas por la tierra y el cielo"34. La divinidad de la torre, del ser masculino que habita en su interior, viene dada por su omnipresencia y control de cada uno de los ángulos de la prisión. La escritora se plantea -como también lo había hecho Ofelia Domínguez en De 6 a 6 - si podría establecerse una relación de dependencia entre aquel que controla y aquel al que se controla. En este sentido, la novela de Agnieska Hernández propone un doble direccionamiento entre el cuerpo que ejerce el sometimiento/el cuerpo que controla y el cuerpo sometido/el cuerpo controlado, teniendo en cuenta las dos partes de esta relación de posesión y dominio. Llega hasta tal punto esta dependencia del que es dominado sobre el que domina que la Jefa de las presas le dice a una de ellas: "Te vas a sorprender cuando veas que ya no

\footnotetext{
${ }^{29}$ A. Hernández Díaz (2009), p. 63.

${ }^{30}$ A. Hernández Díaz (2009), p. 32.

${ }^{31}$ Foucault desarrolla esta doble característica del Panóptico: "El Panóptico es una máquina de disociar la pareja ver-ser visto: en el anillo periférico, se es totalmente visto, sin ver jamás; en la torre central, se ve todo, sin ser jamás visto”. M. Foucault (2009), p. 233-234. Esta condición de ser visto en todo momento Bentham lo considera una ventaja esencial de la estructura panóptica ya que "estar incesantemente a la vista de un inspector, es perder en efecto el poder de hacer mal, y casi el pensamiento de intentarlo". J. Bentham (1989), p. 37.

32 A. Hernández Díaz (2009), p. 20.

${ }^{33}$ A. Hernández Díaz (2009), p. 21, 29.

${ }^{34}$ A. Hernández Díaz (2009), p. 30.
} 
te hace falta. Ya no la necesitamos. Ya no sabemos bien qué hacer con la libertad"35. La voz narrativa también expresa esta necesidad de sentirse controlada una vez que el cuerpo se ha adaptado a esa vigilancia panóptica: "Llegamos al punto de no querer salir del Panóptico; nos sentíamos bien y cuando a alguien le llegaba la libertad buscaba la forma de complicarse con un nuevo delito para no abandonar la prisión" 36 .

En San Lunes el espacio presidiario basado en la arquitectura panóptica es interpretado en términos genéricos: la torre central -el espacio de poder- simboliza la masculinidad y las celdas que forman parte del edificio periférico -el espacio de sometimiento- simbolizan la feminidad: "la torre central es un falo, y nuestras celdas son la vagina que rodea a ese falo, esperando el momento preciso de la copulación" ${ }^{\prime 37}$. En este sentido el espacio arquitectónico del presidio es analizado según los roles de hombre y mujer: el hombre -la torre- es el que domina y controla todo el espacio, y la mujer - la celda- es la que se somete al control de esa mirada eterna. En este punto confluyen la obra de Ofelia Domínguez y de Agnieska Hernández ya que tanto una como otra asemejan el cuerpo de la mujer presa y su representación en el espacio presidiario -cuerpo dócil, cuerpo dominado- con el cuerpo femenino y su posicionamiento con respecto al hombre. El objetivo de las presas al final de San Lunes es unir la torre central y el edificio periférico para que tenga lugar la fusión entre los dos sexos porque "únicamente el equilibrio entre (ellos) puede engendrar una conciliación, la fusión entre dos partes que nunca debieron alejarse" 38 . Esta fusión con el "desconocido atalaya"39 representa simbólicamente esa unión entre sexos que separaría el rol de hombre (cuerpo dominante) y el de la mujer (cuerpo dominado) de tal forma que ya no existiría diferencia entre quien mira/controla/vigila y quien es mirado/controlado/vigilado.

En la novela de Agnieska Hernández, la supuesta perfección del sistema panóptico cuyo objetivo es que el poder se ejerza eficazmente bajo un orden y control sistemático del espacio, se pone en cuestionamiento. Una de las presas se da cuenta de que cada 36 días una de las celdas queda diez minutos sin la vigilancia del "ojo que no duerme ni de día ni de noche" 40 . Por otro lado, debido a una fuerte lluvia la prisión se inunda y es evacuada. El último capítulo de la novela está constituido ficticiamente por testimonios de presas que vivieron la hecatombe del Panóptico. Algunas de sus declaraciones son: "El Panóptico se ahogó a sí mismo", "El Panóptico se destruyó a sí mismo y nosotras no tuvimos ninguna relación con

\footnotetext{
${ }^{35}$ A. Hernández Díaz (2009), p. 62.

${ }^{36}$ A. Hernández Díaz (2009), p. 146.

${ }^{37}$ A. Hernández Díaz (2009), p. 86.

${ }^{38}$ A. Hernández Díaz (2009), p. 87.

${ }^{39}$ A. Hernández Díaz (2009), p. 130.

${ }^{40}$ A. Hernández Díaz (2009), p. 29.
} 
su caída"41. Una de las testigos afirma que el Panóptico no funcionó en la cárcel pero que sin embargo se ha expandido a toda la ciudad: "Fallaron con el Panóptico y ahora se les ocurrió un nuevo sistema de vigilancia... El Panóptico no terminó aquel día. El Panóptico, ahora, está en toda la ciudad. Hay cámaras de seguridad en todas las calles, controlan las llamadas telefónicas de una persona común..." ${ }^{42}$. Es decir, el sistema de control y vigilancia total se traslada del espacio cerrado de la cárcel al espacio abierto de la ciudad. El propio sistema de vigilancia total llevado a cabo dentro de una prisión para dominar a las presas en todo momento se proyecta al afuera de la misma ${ }^{43}$, no ya como espacio arquitectónico sino como mecanismo de control social.

De 6 a 6: la vida en las prisiones cubanas y San Lunes: panóptico en dos estaciones plantean una serie de reflexiones sobre el régimen carcelario cubano -su eficacia/ineficacia y mecanismos de control-y sobre el posicionamiento de la mujer dentro de este espacio de encierro. Ofelia Domínguez en su obra testimonial defiende un cuerpo resistente de mujer que lucha ante un sistema que oprime y desintegra -al igual que la dictadura del general Gerardo Machado- o ante un hombre que domina y somete. Por su parte, Agnieska Hernández sugiere la fisura de un espacio carcelario supuestamente perfecto en el que la mujer asume el rol de cuerpo sometido, y extiende al espacio exterior los mecanismos de control total del presidio. A través de estas dos miradas tan diferentes sobre la cárcel -un testimonio vinculado a un determinado momento histórico y una novela aparentemente atemporal- se enriquece la representación del espacio presidiario en la literatura cubana escrita por mujeres y se plantean nuevas formas de análisis del mismo, bien equiparando los roles de mujer (cuerpo dominado) y hombre (cuerpo dominante) a los del preso y el sistema penitenciario, bien considerando la cárcel como una metáfora del espacio social, al ser incorporados sus mecanismos de vigilancia y control al exterior.

\footnotetext{
${ }^{41}$ A. Hernández Díaz (2009), p. 143-144.

${ }^{42}$ A. Hernández Díaz (2009), p. 144.

${ }^{43}$ La metáfora de Cuba como un "presidio rodeado de agua" se refleja en esta novela que a pesar de no estar contextualizada temporalmente alude a un sistema de poder que ejerce un control total del individuo equiparado al que el presidio ejerce con los presidiarios. La novela finaliza con una nota de la autora fechada en el 2002 en la que menciona el fracaso del Panóptico como proyecto arquitectónico en las prisiones cuyos mecanismos sin embargo sí han sido aplicados en el espacio de poder: "El 24 de febrero de 1994 fue rechazado el proyecto Panóptico por común acuerdo internacional. Las experimentaciones se llevaron a cabo desde 1970 hasta principios de los años noventa, como parte de uno de los grandes proyectos de remozamiento de las prisiones, con el fin de resolver los problemas de la penalidad y ensayar métodos sociales, políticos, éticos, psicológicos y económicos. El Panóptico fracasó como proyecto físico $\mathrm{y}$, sin embargo, los resultados obtenidos son aplicados actualmente como parte de las estructuras de poder”. A. Hernández (2009), p. 148.
} 


\section{Obras citadas}

Bentham, Jeremy: El Panóptico, Madrid, La Piqueta, 1989.

CAIÑAs, Ángeles: Presidio Modelo, La Habana, [s.n.], 1952.

CAIRO, Ana: La revolución del 30 en la narrativa y el testimonio cubanos, La Habana, Editorial Letras Cubanas, 1993.

Cruz Varela, María Elena: Dios en las cárceles de Cuba, Miami, Ediciones Universal, 2001.

DOMíNGUEZ NAVARRO, Ofelia: De 6 a 6: la vida en las prisiones cubanas. México, [s.n.], 1937.

FOUCAULT, Michel: Vigilar y castigar: nacimiento de la prisión (Traducción de Surveiller et punir: naissance de la prison, 1975), Buenos Aires, Siglo XXI Editores, 2009.

: La vida de los hombres infames: ensayos sobre desviación y dominación, Madrid, La Piqueta, 1990.

GONZÁLEZ, Edelmira: Estampas de la cárcel, La Habana, [s.n.], [s.f.].

HERnÁNDEZ DÍAZ, Agnieska: San Lunes. Panóptico en dos estaciones, La Habana,

Caja China, 2009.

: Sol negro, La Habana, Ediciones Unión, 2010.

MARTí, José: El presidio político en Cuba, último diario: y otros textos, Buenos Aires, Editorial Biblos, 1995.

Sociales, 1975.

: Obras completas. Volumen 5, La Habana, Editorial de Ciencias

MONTENEGRO, Carlos: El renuevo y otros cuentos, La Habana, Revista de Avance, 1929.

: Dos barcos, La Habana, Sábado, 1934.

: Hombres sin mujer, México, D.F., Lectorum, 2008.

RODRíGUEZ, Ana y GARVIN, Gleen: Diary of a survivor. Ninenteen years in a Cuban Women's Prison, New York, St. Martin Press, 1995.

TORRIENTE BRAU, Pablo de la: La isla de los 500 asesinatos, La Habana, Ediciones

Nuevo Mundo, 1962.

: Presidio Modelo, La Habana, Instituto Cubano del Libro, 1975.

: "Las mujeres contra Machado", en Testimonios y reportajes, La

Habana, Centro Cultural Pablo de la Torriente Brau, 2009, p.88-115.

: "105 días preso", en Testimonios y reportajes, La Habana, Centro

Cultural Pablo de la Torriente Brau, 2009, p.1-85. 